\title{
Preliminary Efficacy of a Brief Mindfulness Intervention for Procedural Stress in Medical Intern Simulated Performance: A Randomized Controlled Pilot Trial
}

\author{
Elaine O. Cheung, PhD, Jeffrey H. Barsuk, MD, MS, ${ }^{2,3}$ Debi Mitra, MD, ${ }^{2}$ Richard J. Gannotta, DHA, ${ }^{4, *}$ \\ Bruriah Horowitz, Med, Aashish K. Didwania, MD, ${ }^{2,3}$ and David Victorson, PhD $^{1}$
}

\begin{abstract}
Objectives: Simulation-based mastery learning (SBML) programs have been shown to be beneficial to improve procedural skill acquisition. However, simulated procedure performance can be affected by a host of factors, including stress. This investigation examined the preliminary efficacy of bolstering an established SBML program for medical residents with a brief mindfulness intervention (called a PITSTOP) to reduce procedural stress and improve simulator performance.

Design: The study employed a partially blinded, parallel-group, randomized, repeated-measures intention-totreat design. Participants were blinded to the primary outcome (simulator performance) and instead were informed of the study's secondary outcome (stress prevention). The SBML faculty instructors and study investigators were blinded to participants' group assignment.

Settings/location: Northwestern Memorial Hospitals of Chicago.

Subjects: Twenty-six postgraduate year (PGY) 1 internal medicine residents enrolled in a required SBML central venous catheter (CVC) insertion training from June 2015 to January 2018 participated in the study.

Interventions: SBML consists of a simulated skills pretest, deliberate practice, and a simulated skills post-test (within 1 week of pretest). PGY 1 participants were randomly assigned to the PITSTOP intervention (12-min PITSTOP mindfulness training video) or control group (12-min control video on ways to increase physical activity) before the SBML pretest.

Outcome measures: The primary outcome was a comparison of each group's simulator performance during pre- and post-tests. Secondary outcomes were changes in groups' procedural stress during these tests (assessed using self-reported, instructor-rated, and physiologic indicators), and self-reported self-regulation outcomes.

Results: Residents who watched the PITSTOP video before their SBML training made fewer procedural errors relative to controls during their pretest for intrajugular CVC insertion $(p=0.03)$. PITSTOP participants also had lower heart rate $(p=0.03)$ and less visible trembling $(p=0.003)$ relative to controls at the post-test.

Conclusions: This study provides preliminary evidence that a brief, mindfulness intervention may reduce stress during SBML training.
\end{abstract}

Keywords: mindfulness, mindfulness-based stress reduction, stress, anxiety, education, mind-body

Departments of ${ }^{1}$ Medical Social Sciences, ${ }^{2}$ Medicine, and ${ }^{3}$ Medical Education, Northwestern University Feinberg School of Medicine, Chicago, IL.

${ }^{4}$ Northwestern Memorial Hospital, Chicago, IL.

${ }^{*}$ Current Affiliation: Robert F. Wagner Graduate School of Public Service, New York University, New York, NY. 


\section{Introduction}

A PPROXIMATELY 1.5 MILLION preventable adverse events occur annually in the United States, ${ }^{1}$ with projections of 400,000 deaths per year a result of preventable adverse events. ${ }^{2}$ The Institute of Medicine proposes simulation as a potential solution to medical errors. Several simulation interventions have been used to reduce the unacceptable rate of preventable medical errors. ${ }^{3-6}$ For example, Barsuk et al. developed a simulation-based mastery learning (SBML) program for health care providers to practice and demonstrate a high level of competency in complex skills (e.g., insertion of a central venous catheter [CVC]) without risking harm to patients. ${ }^{3-5,7}$ Using a simulator in a controlled setting, health care providers demonstrated mastery through a structured experiential training and evaluation program. The SBML CVC-insertion training program reduced complications during actual patient CVC insertions in the medical intensive care unit, and reduced overall health care costs. ${ }^{8-10}$

Performance measured at pretest during SBML for CVC insertion is widely variable even among health care providers with significant prior clinical experience performing actual CVC insertions. $8,11,12$ There may be a host of factors that influence why CVC procedural skills are so variable despite significant procedure experience. One factor may be that residents experience elevated stress during their SBML training, which may impede their procedural skill acquisition. Although the association between stress and procedural skills acquisition in SBML training has not been evaluated directly, stress has been found to have disruptive effects for learning, performance, and memory formation in other learning contexts. ${ }^{13-17}$ It is plausible that stress may similarly impair learning, mastery, and retention of complex skills, such as CVC insertion. Thus, interventions that teach residents skills for stress management may show promise for improving mastery.

A growing body of research has demonstrated that mindfulness training (typically taught through an 8-week program) has been shown to help reduce provider stress and related diagnostic and medical errors. ${ }^{18-23}$ Mindfulness training enhances an individual's attentional focus and control by allowing for greater self-regulation of cognitive, emotional, and physiologic reactions to stressful and unknown circumstances. ${ }^{24,25}$ With acquired skill and practice, individuals are able to obtain a richer and greater sense of perceptions, leading to a better sense of control and to better informed situational decisions. ${ }^{26}$ Mindfulness training holds promise to help providers better manage the high-risk situations they encounter in their day-to-day practice, such as sudden changes in a patient's condition or dealing with upset family members. Helping providers regulate their stress during these situations might allow them to be more effective in focusing on, and resolving, the problem or issue and make treatment decisions that may improve situational awareness and decrease adverse events. ${ }^{18,21}$

Current mindfulness training programs such as Mindfulness Based Stress Reduction (MBSR) are time-intensive, usually lasting between 18 and 24 h over an 8 -week period. ${ }^{27}$ For busy medical professionals, this can present significant logistical barriers and ultimately affect acceptance, implementation, skill adoption, and scalability. While briefer mindfulness interventions have been created, the majority either rely on a multiweek format with instructors (e.g., 4 weeks instead of 8 weeks) $)^{28-31}$ or simply provide individuals with a guided mindfulness-meditation recording without additional skill instruction from a teacher. To knowledge, the current study is one of the first studies to test the efficacy of a brief (12-min) mindfulness intervention for reducing stress and improving procedural performance in medical trainees.

In MBSR, the acronym and mnemonic "STOP" is taught to students as a part of supporting informal practice. STOP stands for "Stop, Take a few deep breaths, Observe, and Proceed.' Using the STOP acronym as a starting point, the authors adapted it to "PITSTOP" to be more relevant to medical professionals and others who experience high levels of work-related stress and burnout. In this adaptation, PITSTOP stands for Pause; Inhale; Take note of your Self and the Task at hand; Observe the experience without judgment and/or where the mind may have wandered and gently bring it back; and finally, Proceed with the task or activity when ready. By augmenting SBML with brief mindfulness training, such as the PITSTOP, significant potential exists to improve procedural performance.

The current investigation examined whether incorporating a brief mindfulness program to SBML training influenced residents' SBML performance, stress (assessed using self-reported, instructor-rated, and physiologic indicators), and self-regulation abilities (i.e., anxiety, perceived stress, uncertainty intolerance, burnout, cognitive rumination, mindfulness, and their frequency and confidence in engaging in healthy behaviors).

\section{Materials and Methods}

\section{Participants}

Eligible participants were postgraduate year (PGY) 1 internal medicine residents at Northwestern University Feinberg School of Medicine who were eligible to participate in an internal jugular (IJ) and subclavian (SC) CVC insertion SBML training from June 2015 to January 2018. Participants were excluded if they performed regular ( $\geq 3$ times a week) mindfulness meditation for the past year or were enrolled in other studies using psychologic interventions. All participants provided informed consent. The Institutional Review Board at Northwestern University approved this study.

\section{Intervention}

PITSTOP. The authors developed a brief (12-min) video to teach foundational principles of mindfulness, which culminated in the instruction of the PITSTOP technique. A video-based training module facilitates faster, less expensive, and more scalable translation of this intervention in a manner that is more dynamic and easier to understand. $^{32}$ The PITSTOP video is publicly available at: www.consciousnessinhealth.org/resources-tools.html

Control ("Tweak Your Week"). Drawing from publicly available YouTube animation videos of Doctor Mike Evans, the authors created a 12-min video presentation that highlights the importance of increasing physical activity and movement and self-care and offers ways to "tweak your week" using simple strategies. This training served as an attention-matched control condition. 
Design

The current study employed a partially blinded, parallelgroup, randomized, repeated-measures intention-to-treat design. Immediately before completing their SBML training in IJ and SC CVC insertion, medical interns were invited to participate in a stress prevention and wellness promotion research study. Study participants were blinded to the primary outcome (simulator performance) and instead were informed of the study's secondary outcome, intern stress prevention, and wellness promotion. SBML faculty instructors and study investigators were blinded to which group participants were allocated.

Upon arrival to the SBML training session, participants first completed a baseline assessment that included the following self-report measures of self-regulation: anxiety, ${ }^{33}$ perceived stress, ${ }^{34}$ uncertainty intolerance, ${ }^{35}$ rumination, ${ }^{36}$ burnout, ${ }^{37}$ mindfulness, ${ }^{38}$ and enacted health behaviors. This assessment took $\sim 15 \mathrm{~min}$ to complete. Next, participants watched either a brief 12-min video on the PITSTOP procedure (intervention condition) or a brief 12-min video on increasing physical activity (control condition), based on randomization. After watching the video, participants completed the same self-report measures (postvideo assessment) that took $\sim 15 \mathrm{~min}$ to complete. In addition, participants also reported their interest and confidence in practicing the skill they learned in the video. Participants were then asked to rate their CVC-insertion self-confidence on a scale from $0=$ low to $100=$ very high as well as their experience with each procedure by answering the number of procedures they had personally performed. Given that a large proportion of participants responded 0 for each procedure, the authors dichotomized participants' confidence and experience scores as follows: $0=$ no confidence/experience, $1=$ any confidence/experience (score $>0$ ). They calculated sum scores of participants' dichotomous confidence and experience scores across the insertions.

Immediately after completing the postvideo assessment, participants completed their SBML training with a faculty instructor. The SBML training is described elsewhere. ${ }^{3-6}$ Briefly, participants first perform a simulated CVC-insertion test (pretest) using a 29-item checklist for both IJ and SC CVC insertions. ${ }^{3-6}$ Each action on the checklist was listed in order and given equal weight using a dichotomous scoring system ( $1=$ done correctly, $0=$ done incorrectly). Next, they watch a lecture and video with information about the procedure. They then return to the simulator to participate in deliberate practice with directed feedback from a faculty instructor. Finally, participants take a simulated post-test using the same checklist on a different day, within 1 week of deliberate practice. All participants are required to meet or exceed a minimum passing score before completion of training. ${ }^{3-6}$

After each test (pretest and post-test), the instructor asked participants how nervous they felt during the session (both IJ and $\mathrm{SC}$ combined), from $0=$ not at all to $10=$ extremely. In addition, the instructor rated whether participants were visibly trembling during the session (both IJ and SC combined) (1=yes, $0=$ no). Participants wore the Empatica E4 wristband $^{39}$ that collected their heart rate data during the training. ARTiiFACT $^{40}$ heart rate artifact processing and heart rate variability (HRV) analysis software was used to detect and process artifacts in the data and to calculate HRV indices of interest. From these data, participants' average heart rate during each session was calculated as a physiologic indicator of their state levels of stress (with higher average heart rate suggestive of greater stress). In addition, the authors calculated three indices of participants' HRV during the session: standard deviation of normal-to-normal $(\mathrm{NN})$ intervals, root mean square of successive differences in intervals between two successive R-waves (RR intervals), and the percentage of successive RR intervals that differ by more than $50 \mathrm{msec}$ (pNN50). ${ }^{41}$ For all three indices of HRV, higher numbers have been associated with greater stress management, ${ }^{42,43}$ although some evidence suggests that higher HRV is not always better. ${ }^{44}$

\section{Statistical analyses}

Cronbach's alpha was calculated to determine the reliability of the self-regulation measures. To examine baseline between-group differences on demographic and selfregulation, independent $t$-tests were performed for continuous outcomes and $\chi^{2}$ tests for categorical outcomes. The Mann-Whitney $U$ test was used to examine between-group differences on participants' CVC performance, because data were skewed. Independent $t$-tests were used to examine between-group differences in nervousness and the physiologic outcomes. $\chi^{2}$ tests were used to compare betweengroup differences in trembling. Mixed-effects modeling ${ }^{45}$ was used to compare between-group changes from baseline to the postvideo assessment in the self-regulation measures. Time (dummy coded: $0=$ baseline, $1=$ postvideo) was modeled at Level 1 and condition at Level 2 (dummy coded: $0=$ control, $1=$ PITSTOP). The authors consider statistically significant results as findings with a $p<0.05$.

Despite randomization, there were baseline group differences on anxiety, perceived stress, uncertainty intolerance, rumination, mindfulness, and interest. Additional analyses were conducted adjusting for differences. Due to power limitations, the authors ran separate analyses controlling for each covariate separately. Specifically, analysis of covariance tests were conducted for continuous outcomes, and binary logistic regressions were conducted for categorical outcomes, adjusting for each covariate separately. Finally, mixed-effects models were conducted to examine between-group changes from baseline to the postvideo assessment in the self-reported, selfregulation outcomes, again adjusting for each covariate separately. All analyses were conducted using IBM SPSS Statistics Version 23.0 for Windows (IBM Corp, Armonk, NY).

\section{Results}

Descriptive statistics are reported in Table 1. Forty-seven PGY-1 residents were eligible for the study. Twenty-six $(55 \%)$ PGY 1 internal medicine residents participated (14 Female, 12 Male; $\left.M_{\text {age }}=28.50, S D=2.45\right)$. Participants were randomly assigned to the PITSTOP $(n=13)$ or control condition $(n=13)$. Nineteen participants $(73 \%)$ were retained through posttest. Figure 1 shows a Consort diagram of enrollment, reflecting a retention rate of $76 \%$ for the intervention and $69 \%$ for the control.

\section{Simulation performance}

As seen in Table 2, PITSTOP participants had superior IJ performance at pretest $(M d n=78 \%$ correct, interquartile range $[\mathrm{IQR}]=28 \%)$ relative to controls $(M d n=45 \%$ correct, 
Table 1. Sample Characteristics by Condition

\begin{tabular}{lcccc}
\hline & $\begin{array}{c}\text { Total sample } \\
(\mathrm{n}=26)\end{array}$ & $\begin{array}{c}\text { PITSTOP } \\
\text { intervention } \\
(\mathrm{n}=13)\end{array}$ & $\begin{array}{c}\text { Control } \\
(\mathrm{n}=13)\end{array}$ & $\begin{array}{c}\text { Group } \\
\text { difference } \\
\text {-Value }\end{array}$ \\
\hline Age & $28.50(2.45)$ & $27.92(2.47)$ & $29.08(2.40)$ & 0.24 \\
Gender & $14(53.8 \%)$ & $6(46.2 \%)$ & $8(61.5 \%)$ & - \\
$\quad$ Female & $12(46.2 \%)$ & $7(53.8 \%)$ & $5(38.5 \%)$ & - \\
$\quad$ Male & $0(0 \%)$ & $0(0 \%)$ & $0(0 \%)$ & - \\
$\quad$ Other & $4(15.4 \%)$ & $1(7.7 \%)$ & $3(23.1 \%)$ & 0.28 \\
Hispanic & $0.61(0.50)$ & $0.73(0.47)$ & $0.50(0.52)$ & 0.29 \\
Clinical experience with CVC insertions (0 to 2) & $1.46(0.76)$ & $1.69(0.63)$ & $1.23(0.83)$ & 0.12 \\
Procedural confidence with CVC insertions (0 to 2) & $2.96(1.08)$ & $2.54(1.13)$ & $3.45(0.82)$ & 0.04 \\
Interest in practicing skill learned (1 to 4) & $2.21(0.93)$ & $2.00(0.91)$ & $2.45(0.93)$ & 0.24 \\
Confidence in practicing skill learned (1 to 4) & $55.51(6.79)$ & $52.43(7.03)$ & $58.59(5.11)$ & 0.02 \\
Anxiety (T-score) & $17.19(3.97)$ & $15.61(3.57)$ & $18.77(3.83)$ & 0.04 \\
Perceived stress (0 to 40) & $1.63(0.69)$ & $1.28(0.54)$ & $1.99(0.64)$ & 0.005 \\
Uncertainty intolerance (0 to 4) & $2.23(0.68)$ & $1.97(0.71)$ & $2.49(0.56)$ & 0.05 \\
Rumination & $39.23(20.15)$ & $34.31(14.13)$ & $44.15(24.36)$ & 0.22 \\
Burnout (0 to 132) & $3.84(0.62)$ & $4.12(0.56)$ & $3.56(0.55)$ & 0.02 \\
Mindfulness (1 to 6) & $2.24(0.32)$ & $2.18(0.36)$ & $2.31(0.28)$ & 0.31 \\
Health behavior: frequency (0 to 4) & $2.47(0.50)$ & $2.61(0.43)$ & $2.32(0.53)$ & 0.13 \\
Health behavior: confidence (0 to 4) & &
\end{tabular}

Values represent mean (SD) for continuous outcomes and $n(\%)$ for categorical outcomes.

CVC, central venous catheter.

$\mathrm{IQR}=41 \%)(p=0.03)$. In additional analyses adjusting for baseline group differences, the intervention effect on IJ performance remained significant controlling for interest $(p=0.02)$ and rumination $(p=0.02)$, and was nonsignificant when controlling for baseline differences in uncertainty intolerance $(p=0.05)$, anxiety $(p=0.07)$, perceived stress $(p=0.06)$, and mindfulness $(p=0.10)$. PITSTOP participants did not significantly differ from controls in IJ at the post-test, and this remained nonsignificant in analyses adjusting for covariates $(p>0.10)$.

PITSTOP participants did not significantly differ from controls in SC performance at pretest or post-test, and this remained nonsignificant in analyses adjusting for covariates $(p>0.10)$.

\section{Stress indicators}

Self-rated nervousness. As seen in Table 3, there were no significant between-group differences in participants' self-rated nervousness at IJ and SC pretest or post-test. This remained nonsignificant in analyses adjusting for covariates $(p>0.10)$.

Visible trembling. As seen in Table 3, there was no significant between-group difference in participants' visible trembling at the pretest. This remained nonsignificant in analyses adjusting for covariates $(p>0.10)$. However, a significant group difference was observed in visible trembling at the post-test, such that PITSTOP participants were less likely than controls to show visible trembling (PITSTOP: $12.5 \%$ and Control: $87.5 \%)(p=0.003)$. The statistically significant intervention effects on trembling at the post-test remained significant controlling for participants' interest $(p=0.03)$, and baseline differences in anxiety $(p=0.02)$, perceived stress $(p=0.01)$, uncertainty intolerance $(p=0.04)$, mindfulness $(p=0.04)$, and rumination $(p=0.02)$.
Physiologic indicators. As seen in Table 3, there was no significant between-group difference in heart rate at the pretest. This remained nonsignificant in analyses adjusting for covariates $(p>0.10)$. However, a significant group difference was observed in heart rate at the post-test, such that PITSTOP participants had lower heart rate $(M=82.89$, $S D=6.19)$ relative to controls $(M=97.88, S D=18.00)$ $(p=0.03)$. The statistically significant intervention effects on heart rate at the post-test remained statistically significant when controlling for participants' interest $(p=0.03)$, and baseline differences in anxiety $(p=0.008)$, perceived stress $(p=0.04)$, uncertainty intolerance $(p=0.02)$, mindfulness $(p=0.03)$, and rumination $(p=0.007)$.

No significant between-group differences in HRV were observed at either the pretest or the post-test. This remained nonsignificant in analyses adjusting for covariates $(p>0.10)$.

\section{Self-regulation outcomes}

Table 4 presents scale reliabilities and results for the mixed-effects models comparing between-group changes from baseline to the postvideo assessment in self-regulation outcomes. No significant Condition $\times$ Time interactions were observed, and these findings remained nonsignificant in analyses adjusting for covariates $(p>0.10)$.

\section{Discussion}

To knowledge, this is the first study to evaluate the effects of a mindfulness intervention on stress and procedural errors. The present findings provide preliminary evidence suggesting that a brief mindfulness intervention, such as the PITSTOP, may be associated with lower procedural stress (i.e., lower heart rate and less visible trembling). The authors acknowledge that recurrent direct observation of skills and performance may mitigate some of the stress experienced by 
FIG. 1. Consort diagram. PGY 1, postgraduate year 1; SBML, simulation-based mastery learning.

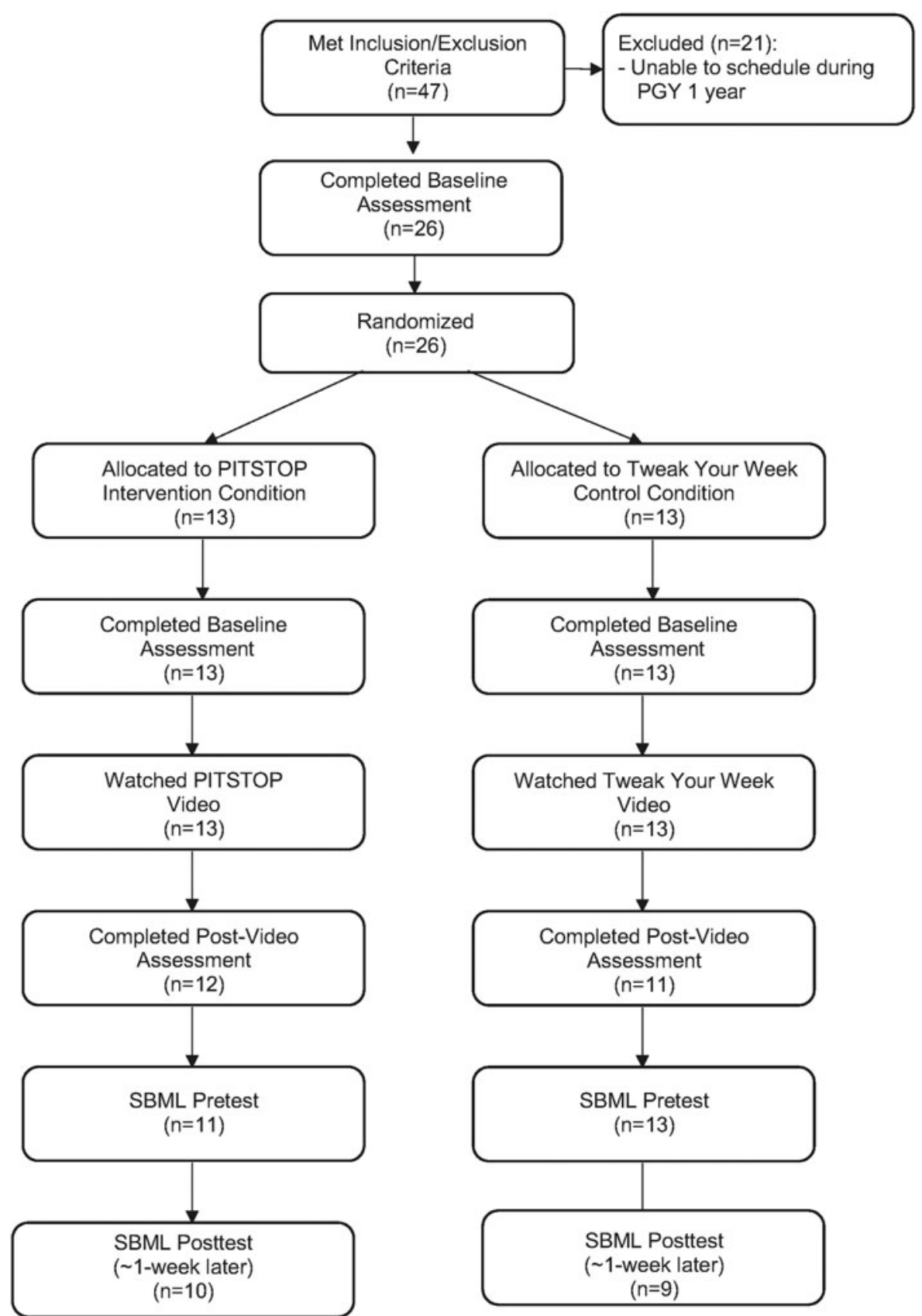

Table 2. Simulation Performance (\% Steps Correct) at Pretest and Post-test by Condition

\begin{tabular}{|c|c|c|c|c|c|c|}
\hline \multirow[b]{2}{*}{ Outcomes } & \multirow{2}{*}{$\begin{array}{l}\text { Pretest } \\
\text { Median }\end{array}$} & \multicolumn{2}{|c|}{ Mann-Whitney test } & \multirow{2}{*}{$\begin{array}{c}\text { Post-test } \\
\text { Median }\end{array}$} & \multicolumn{2}{|c|}{ Mann-Whitney test } \\
\hline & & $\mathrm{U}$ & $\mathrm{p}$ & & $\mathrm{U}$ & $\mathrm{p}$ \\
\hline $\begin{array}{l}\text { IJ insertion sc } \\
\text { PITSTOP } \\
\text { Control }\end{array}$ & $\begin{array}{l}77.6 \% \\
44.8 \%\end{array}$ & 33.00 & 0.03 & $\begin{array}{r}96.6 \% \\
100.0 \%\end{array}$ & 24.00 & 0.10 \\
\hline $\begin{array}{c}\text { SC insertion } \\
\text { PITSTOP } \\
\text { Control }\end{array}$ & $\begin{array}{l}58.6 \% \\
31.0 \%\end{array}$ & 39.00 & 0.11 & $\begin{array}{l}96.6 \% \\
96.6 \%\end{array}$ & 43.50 & 0.91 \\
\hline
\end{tabular}

IJ, internal jugular; SC, subclavian. 
Table 3. Stress Indicators During Pretest and Post-test by Condition

\begin{tabular}{|c|c|c|c|c|c|c|c|c|}
\hline \multirow[b]{2}{*}{ Outcomes } & \multicolumn{2}{|c|}{ SBML pretest } & \multicolumn{2}{|c|}{$\begin{array}{l}\text { SBML pretest } \\
\text { Between-group } \\
\text { comparison tests }\end{array}$} & \multicolumn{2}{|c|}{$\begin{array}{c}\text { SBML 1-week } \\
\text { post-test }\end{array}$} & \multicolumn{2}{|c|}{$\begin{array}{l}\text { SBML post-test } \\
\text { Between-group } \\
\text { comparison tests }\end{array}$} \\
\hline & $\mathrm{M}$ or $\mathrm{n}$ & $\mathrm{SD}$ or $\%$ & $\mathrm{t}$ or $\chi^{2}$ & $\mathrm{p}$ & $\mathrm{M}$ or $\mathrm{n}$ & $\mathrm{SD}$ or $\%$ & t or $\chi^{2}$ & $\mathrm{p}$ \\
\hline \multicolumn{9}{|c|}{ Self-rated nervousness ( 0 to 10 ) } \\
\hline PITSTOP & 4.54 & 1.75 & -1.08 & 0.29 & 3.85 & 2.54 & -0.22 & 0.83 \\
\hline Control & 5.50 & 2.45 & & & 4.11 & 2.67 & & \\
\hline \multicolumn{9}{|c|}{ Visible trembling $(0=$ no, $1=$ yes $)$} \\
\hline PITSTOP & 2 & $18.2 \%$ & 3.23 & 0.07 & 1 & $10.0 \%$ & 8.93 & 0.003 \\
\hline Control & 7 & $53.8 \%$ & & & 7 & $77.8 \%$ & & \\
\hline \multicolumn{9}{|l|}{ Heart rate } \\
\hline PITSTOP & 87.60 & 7.14 & -1.15 & 0.27 & 82.89 & 6.19 & -2.35 & 0.03 \\
\hline Control & 94.55 & 17.87 & & & 97.88 & 18.00 & & \\
\hline \multicolumn{9}{|l|}{ HRV: SDNN } \\
\hline PITSTOP & 66.30 & 15.59 & -1.17 & 0.26 & 73.00 & 8.80 & -0.49 & 0.63 \\
\hline Control & 74.18 & 15.29 & & & 77.50 & 26.12 & & \\
\hline \multicolumn{9}{|c|}{ HRV: RMSDD } \\
\hline PITSTOP & 58.80 & 12.46 & -1.07 & 0.30 & 63.44 & 8.28 & -0.43 & 0.65 \\
\hline Control & 65.91 & 17.35 & & & 66.38 & 18.81 & & \\
\hline \multicolumn{9}{|l|}{ HRV: pNN50 } \\
\hline PITSTOP & 30.80 & 11.07 & -0.98 & 0.34 & 33.44 & 5.83 & -0.68 & 0.51 \\
\hline Control & 36.00 & 12.98 & & & 36.75 & 13.29 & & \\
\hline
\end{tabular}

HRV, heart rate variability; NN intervals, normal-to-normal intervals; pNN50, percentage of successive RR intervals that differ by more than $50 \mathrm{msec}$; RMSDD, root mean square of successive differences in RR intervals; RR intervals, intervals between two successive R-waves; SBML, simulation-based mastery learning; SDNN, standard deviation of NN intervals.

Table 4. Self-Reported Self-Regulation Outcomes by Condition and Reliabilities (Cronbach's $\alpha$ of Measures)

\begin{tabular}{|c|c|c|c|c|c|c|c|c|}
\hline \multirow[b]{2}{*}{ Outcomes } & \multicolumn{3}{|c|}{ Baseline } & \multicolumn{3}{|c|}{ Postvideo assessment } & \multicolumn{2}{|c|}{ Condition $\times$ time interaction } \\
\hline & $\alpha$ & $\mathrm{M}$ & $S E$ & $\alpha$ & M & $S E$ & $\mathrm{~b}$ & $\mathrm{p}$ \\
\hline $\begin{array}{l}\text { Anxiety } \\
\text { PITSTOP } \\
\text { Control }\end{array}$ & 0.89 & $\begin{array}{l}52.43 \\
58.59\end{array}$ & $\begin{array}{l}1.92 \\
1.92\end{array}$ & 0.92 & $\begin{array}{l}51.95 \\
57.69\end{array}$ & $\begin{array}{l}2.00 \\
2.09\end{array}$ & -0.42 & 0.92 \\
\hline $\begin{array}{l}\text { Perceived stre } \\
\text { PITSTOP } \\
\text { Control }\end{array}$ & 0.55 & $\begin{array}{l}15.61 \\
18.77\end{array}$ & $\begin{array}{l}1.37 \\
1.37\end{array}$ & 0.74 & $\begin{array}{l}15.42 \\
18.18\end{array}$ & $\begin{array}{l}1.43 \\
1.49\end{array}$ & -0.39 & 0.89 \\
\hline $\begin{array}{l}\text { Uncertainty i } \\
\text { PITSTOP } \\
\text { Control }\end{array}$ & $\begin{array}{c}\text { erance } \\
0.90\end{array}$ & $\begin{array}{l}1.28 \\
1.99\end{array}$ & $\begin{array}{l}0.17 \\
0.17\end{array}$ & 0.93 & $\begin{array}{l}1.20 \\
2.02\end{array}$ & $\begin{array}{l}0.18 \\
0.19\end{array}$ & 0.10 & 0.77 \\
\hline $\begin{array}{c}\text { Rumination } \\
\text { PITSTOP } \\
\text { Control }\end{array}$ & 0.88 & $\begin{array}{l}1.97 \\
2.49\end{array}$ & $\begin{array}{l}0.18 \\
0.18\end{array}$ & 0.84 & $\begin{array}{l}1.88 \\
2.40\end{array}$ & $\begin{array}{l}0.19 \\
0.20\end{array}$ & 0.01 & 0.99 \\
\hline $\begin{array}{l}\text { Burnout } \\
\text { PITSTOP } \\
\text { Control }\end{array}$ & 0.92 & $\begin{array}{l}34.31 \\
44.15\end{array}$ & $\begin{array}{l}5.90 \\
5.90\end{array}$ & 0.94 & $\begin{array}{l}36.00 \\
41.36\end{array}$ & $\begin{array}{l}6.15 \\
6.42\end{array}$ & -4.48 & 0.71 \\
\hline $\begin{array}{c}\text { Mindfulness } \\
\text { PITSTOP } \\
\text { Control }\end{array}$ & 0.86 & $\begin{array}{l}4.12 \\
3.56\end{array}$ & $\begin{array}{l}0.19 \\
0.19\end{array}$ & 0.93 & $\begin{array}{l}3.96 \\
3.67\end{array}$ & $\begin{array}{l}0.20 \\
0.21\end{array}$ & 0.27 & 0.50 \\
\hline $\begin{array}{l}\text { Health behav } \\
\text { PITSTOP } \\
\text { Control }\end{array}$ & $\begin{array}{l}\text { frequ } \\
0.39\end{array}$ & $\begin{array}{l}2.18 \\
2.31\end{array}$ & $\begin{array}{l}0.09 \\
0.09\end{array}$ & 0.56 & $\begin{array}{l}2.14 \\
2.34\end{array}$ & $\begin{array}{l}0.10 \\
0.10\end{array}$ & 0.06 & 0.75 \\
\hline $\begin{array}{l}\text { Health behav } \\
\text { PITSTOP } \\
\text { Control }\end{array}$ & $\begin{array}{l}\text { confic } \\
0.67\end{array}$ & $\begin{array}{l} \\
2.62 \\
2.32\end{array}$ & $\begin{array}{l}0.14 \\
0.14\end{array}$ & 0.64 & $\begin{array}{l}2.57 \\
2.36\end{array}$ & $\begin{array}{l}0.15 \\
0.16\end{array}$ & 0.09 & 0.77 \\
\hline
\end{tabular}


residents during SBML pre- and post-tests. However, residents at this institution participate in a significant number of direct observations using both live and simulated assessments. Therefore, they observe that much of the stress experienced during SBML CVC training originates from the procedure itself.

Participants who watched a brief mindfulness video before their SBML training made fewer procedural errors relative to controls in their IJ (but not SC) pretest. One reason why IJ performance may have been more responsive relative to SC performance may be because SC insertions tend to be more technically difficult and people tend to perform worse on SC insertions (vs. IJ insertions) more generally, ${ }^{6,8,12}$ In addition, residents rarely, if ever, insert SC lines at this institution in actual patients, and so, they may have felt less nervous about worse performance. IJ insertions on the contrary are much more relevant to residents' future performance with patients. There were no significant between-group differences in participants' simulation performance at the post-test, likely due to ceiling effects in performance (both groups achieved the minimum passing standard at the first iteration of posttest). In addition, PITSTOP participants exhibited lower heart rate and less visible trembling relative to controls at the post-test, which provides some initial evidence suggesting that they may have been better able to manage their stress at post-test. Together, these findings underscore the potential for SBML training programs to be augmented with a brief mindfulness intervention to facilitate the management of procedural stress during medical training.

Moreover, PITSTOP appeared to have differential consequences for stress depending on how stress was measured. Specifically, some of the physiologic and behavioral indicators of stress (e.g., heart rate and instructor-rated trembling) appeared to be responsive to PITSTOP, whereas self-reported measures of stress (e.g., self-rated nervousness, perceived stress, and self-reported anxiety) were not. Perhaps this discrepancy may be due to residents' reluctance to report feelings of stress and anxiety to their instructors. Alternatively, self-report measures may be less sensitive at detecting change in participants' state levels of stress relative to the physiologic and observer-rated indicators. Nevertheless, these findings underscore the benefits of assessing constructs such as stress using multiple different channels (e.g., physiologic, selfreport, and nonverbal/behavioral coding). As the literature develops, particularly with respect to which measures of stress are most sensitive to intervention, researchers would do well to select measures that may best capture potential intervention effects. In addition, future research should include additional physiologic markers, including markers of parasympathetic activation (e.g., respiratory sinus arrhythmia), as well as markers that may distinguish between positive versus negative types of stress responses (e.g., "challenge vs. threat" and "eustress vs. distress"). ${ }^{46,47}$

Strengths of the current research include its coapplication of both simulation and mindfulness-based training for interns. To knowledge, no combined training program has been developed to reduce errors and address self-regulation among providers. Limitations of the study include that the study was performed at a single institution, with a small number of participants, and a $27 \%$ attrition rate. The authors were unable to enroll the entire cohort of PGY-1 residents due to a competing psychologic intervention study and ex- perienced scheduling difficulties. It is possible the PGY1 residents who enrolled and were able to complete the entire protocol may have been more motivated, which may have resulted in selection biases toward superior performance and differences in the effect of mindfulness on anxiety or stress. However, randomization should have minimized this potential threat between groups. Of note, all residents who were unable to complete the SBML intervention during their intern year completed the CVC SBML during PGY-2 or 3 years, but were no longer eligible for inclusion in this study.

An additional limitation of the current research was that despite randomization, there was an unexpected imbalance between groups on several baseline characteristics (i.e., selfreported uncertainty tolerance, anxiety, perceived stress, and trait mindfulness). Prior research suggests that studies with small sample sizes $(n<100)$ may be susceptible to imbalances between groups on baseline characteristics. ${ }^{46}$ The current study addressed these baseline group differences by adjusting for each of these baseline group differences in additional analyses. These additional analyses found that the intervention effects on visible trembling and heart rate at post-test remained statistically significant when adjusting for each of these baseline group differences, suggesting that these results may be robust against these baseline group differences. However, the intervention effects on IJ performance at pretest were not robust to adjusting for baseline group differences. Thus, this unexpected imbalance between groups at baseline impedes the ability to draw conclusions from the current research, particularly as they pertain to simulator performance.

Future studies are needed using larger samples and longer follow-up periods to examine whether supplementing SBML training with PITSTOP helps residents retain SBML mastery over time. Although all residents achieved mastery at first post-test, regardless of whether they received PITSTOP or not (scores $>96 \%$ correct), mindfulness training may have beneficial effects on SBML learning, mastery, and retention that emerge over longer periods of time (e.g., 6-month reevaluation). In the current study, the authors posited that watching a brief (12-min) video on mindfulness would influence participants' ability to manage stress during the SBML training and post-test, and that this improved stress management may in turn have more lasting, long-term consequences for procedural skill mastery over time. It is possible that the early benefits of mindfulness training on resident learning during the initial SBML training session may translate to a deeper encoding of the procedural skills, and a greater likelihood that the skills are retained over time. However, the current study did not examine whether the PITSTOP intervention may have longer lasting effects beyond the SBML training and post-test sessions. Future research should include longer follow-up periods and examine whether mindfulness training improves other potential pathways, such as procedural memory. Finally, participants' breathing rate during the mindfulness induction and the SBML training may have influenced the outcome measures, and the authors did not collect measures of participants' breathing rate. Future research should control for this potential confound.

\section{Conclusion}

In summary, brief mindfulness training such as the PITSTOP offers a simple, scalable adjuvant to improve selfregulation, and to potentially enhance and reinforce medical 
learning and performance. Over time through practice, the authors may find it is not even necessary for individuals to remember exactly what PITSTOP refers to, except that it offers a moment of self-care through briefly dropping into oneself with mindful awareness. The findings from this simulation-based study can be disseminated to larger training programs and clinical practice care settings across the country through practice-based initiatives.

\section{Acknowledgment}

Dr. Cheung was supported by a National Science Foundation Social Behavioral and Economics postdoctoral fellowship (NSF\# 1714952).

\section{Author Disclosure Statement}

The authors report no competing financial interests. No commercial party having a direct financial interest in the results of the research supporting this article has or will confer a benefit upon the authors or upon any organization with which the authors are associated.

\section{Funding Information}

The authors report no external funding source for this study.

\section{References}

1. Bates DW. Preventing medication errors: A summary. Am J Health Syst Pharm 2007;64(14 Suppl 9):S3-S9; quiz S24-S26.

2. James JT. A new, evidence-based estimate of patient harms associated with hospital care. J Patient Saf 2013;9:122-128.

3. Barsuk JH, Cohen ER, Potts S, et al. Dissemination of a simulation-based mastery learning intervention reduces central line-associated bloodstream infections. BMJ Qual Saf 2014;23:749-756.

4. Barsuk JH, Cohen ER, Vozenilek JA, et al. Simulationbased education with mastery learning improves paracentesis skills. J Grad Med Educ 2012;4:23-27.

5. Barsuk JH, Cohen ER, Feinglass J, et al. Unexpected collateral effects of simulation-based medical education. Acad Med 2011;86:1513-1517.

6. Cohen ER, Barsuk JH, McGaghie WC, Wayne DB. Raising the bar: Reassessing standards for procedural competence. Teach Learn Med 2013;25:6-9.

7. Barsuk JH, Cohen ER, Caprio T, et al. Simulation-based education with mastery learning improves residents' lumbar puncture skills. Neurology 2012;79:132-137.

8. Barsuk JH, McGaghie WC, Cohen ER, et al. Simulationbased mastery learning reduces complications during central venous catheter insertion in a medical intensive care unit. Crit Care Med 2009;37:2697-2701.

9. Barsuk JH, Cohen ER, Feinglass J, et al. Use of simulationbased education to reduce catheter-related bloodstream infections. Arch Intern Med 2009;169:1420-1423.

10. Cohen ER, Feinglass J, Barsuk JH, et al. Cost savings from reduced catheter-related bloodstream infection after simulation-based education for residents in a medical intensive care unit. Simul Healthc 2010;5:98-102.

11. Barsuk JH, Cohen ER, McGaghie WC, Wayne DB. Longterm retention of central venous catheter insertion skills after simulation-based mastery learning. Acad Med 2010; 85:S9-S12.

12. Barsuk JH, McGaghie WC, Cohen ER, et al. Use of simulation-based mastery learning to improve the quality of central venous catheter placement in a medical intensive care unit. J Hosp Med 2009;4:397-403.

13. Schwabe L, Wolf OT. Learning under stress impairs memory formation. Neurobiol Learn Mem 2010;93:183188 .

14. Ashcraft MH, Kirk EP. The relationships among working memory, math anxiety, and performance. J Exp Psychol Gen 2001;130:224.

15. Schwabe L, Joëls M, Roozendaal B, et al. Stress effects on memory: An update and integration. Neurosci Biobehav Rev 2012;36:1740-1749.

16. Schwabe L, Wolf OT. Timing matters: Temporal dynamics of stress effects on memory retrieval. Cogn Affect Behav Neurosci 2014;14:1041-1048.

17. Zeidner M. Anxiety in education. In: Pekrun R, Linnenbrink-Garcia L, eds. International Handbook of Emotions in Education. New York: Routledge, 2014:275-298.

18. Sibinga EM, Wu AW. Clinician mindfulness and patient safety. JAMA 2010;304:2532-2533.

19. Warnecke E, Quinn S, Ogden K, et al. A randomised controlled trial of the effects of mindfulness practice on medical student stress levels. Med Educ 2011;45:381-388.

20. Goodman MJ, Schorling JB. A mindfulness course decreases burnout and improves well-being among healthcare providers. Int J Psychiatry Med 2012;43:119-128.

21. Brady S, O'Connor N, Burgermeister D, Hanson P. The impact of mindfulness meditation in promoting a culture of safety on an acute psychiatric unit. Perspect Psychiatr Care 2012;48:129-137.

22. Beckman HB, Wendland M, Mooney C, et al. The impact of a program in mindful communication on primary care physicians. Acad Med 2012;87:815-819.

23. Krasner MS, Epstein RM, Beckman H, et al. Association of an educational program in mindful communication with burnout, empathy, and attitudes among primary care physicians. JAMA 2009;302:1284-1293.

24. Bishop SR, Lau M, Shapiro S, et al. Mindfulness: A proposed ooperational definition. Clin Psychol Sci Pract 2004; 11:230-241.

25. Hulsheger UR, Alberts HJ, Feinholdt A, Lang JW. Benefits of mindfulness at work: The role of mindfulness in emotion regulation, emotional exhaustion, and job satisfaction. J Appl Psychol 2013;98:310-325.

26. Vago DR, Silbersweig DA. Self-awareness, self-regulation, and self-transcendence (S-ART): A framework for understanding the neurobiological mechanisms of mindfulness. Front Hum Neurosci 2012;6:296.

27. Kabat-Zinn J. Full Catastrophe Living: Using the Wisdom of your Mind to Face Stress, Pain and Illness. New York: Dell Publishing, 1990.

28. Moore A, Gruber T, Derose J, Malinowski P. Regular, brief mindfulness meditation practice improves electrophysiological markers of attentional control. Front Hum Neurosci 2012;6:18.

29. Jha AP, Krompinger J, Baime MJ. Mindfulness training modifies subsystems of attention. Cogn Affect Behav Neurosci 2007;7:109-119.

30. Tang YY, Ma Y, Wang J, et al. Short-term meditation training improves attention and self-regulation. Proc Natl Acad Sci U S A 2007;104:17152-17156. 
31. Larson MJ, Steffen PR, Primosch M. The impact of a brief mindfulness meditation intervention on cognitive control and error-related performance monitoring. Front Hum Neurosci 2013;7:308.

32. Weeks BK, Horan SA. A video-based learning activity is effective for preparing physiotherapy students for practical examinations. Physiotherapy 2013;99:292-297.

33. Pilkonis PA, Choi SW, Reise SP, et al. Item banks for measuring emotional distress from the Patient-Reported Outcomes Measurement Information System (PROMIS(R)): Depression, anxiety, and anger. Assessment 2011;18:263283.

34. Cohen S, Kamarck T, Mermelstein R. A global measure of perceived stress. J Health Soc Behav 1983;24:385-396.

35. Carleton RN, Norton MA, Asmundson GJ. Fearing the unknown: A short version of the Intolerance of Uncertainty Scale. J Anxiety Disord 2007;21:105-117.

36. Trapnell PD, Campbell JD. Private self-consciousness and the five-factor model of personality: Distinguishing rumination from reflection. J Pers Soc Psychol 1999;76:284304.

37. Maslach C. What have we learned about burnout and health? Psychol Health 2001;16:607-611.

38. Brown KW, Ryan RM. The benefits of being present: Mindfulness and its role in psychological well-being. J Pers Soc Psychol 2003;84:822-848.

39. McCarthy C, Pradhan N, Redpath C, Adler A. Validation of the Empatica E4 wristband. Paper presented at: Student Conference (ISC), 2016 IEEE EMBS International. Ottawa, Ontario, 2016.

40. Kaufmann T, Sütterlin S, Schulz SM, Vögele C. ARTiiFACT: A tool for heart rate artifact processing and heart rate variability analysis. Behav Res Methods 2011;43: 1161-1170.

41. Shaffer F, Ginsberg JP. An overview of heart rate variability metrics and norms. Front Public Health 2017;5:258.

42. Appelhans BM, Luecken LJ. Heart rate variability as an index of regulated emotional responding. Rev Gen Psychol 2006;10:229-240.

43. Acharya UR, Joseph KP, Kannathal N, et al. Heart rate variability: A review. Med Biol Eng Comput 2006;44: 1031-1051.

44. Stein PK, Domitrovich PP, Hui N, et al. Sometimes higher heart rate variability is not better heart rate variability: Results of graphical and nonlinear analyses. J Cardiovasc Electrophysiol 2005;16:954-959.

45. Singer JD, Willett JB. Applied Longitudinal Data Analysis: Modeling Change and Event Occurrence. New York: Oxford University Press, 2003.

46. Kang M, Ragan BG, Park J-H. Issues in outcomes research: An overview of randomization techniques for clinical trials. J Athl Train 2008;43:215-221.

47. Aschbacher K, Mason AE. Eustress, distress, and oxidative stress: Promising pathways for mind-body medicine. In: Sies H, ed. Oxidative Stress. London: Elsevier, 2020:583-617.

Address correspondence to: David Victorson, PhD

Department of Medical Social Sciences Northwestern University Feinberg School of Medicine 2205 Tech Drive, Hogan Building (Suite 2-120) Evanston, IL 60208

Email: d-victorson@northwestern.edu 